\title{
BMJ Open Association between preconception maternal stress and offspring birth weight: findings from an Australian longitudinal data linkage study
}

\author{
Melissa L Harris (D) , ${ }^{1}$ Alexis J Hure, ${ }^{1,2}$ Elizabeth Holliday $(D),{ }^{2}$ Catherine Chojenta, ${ }^{1}$ \\ Amy E Anderson, ${ }^{1}$ Deborah Loxton ${ }^{1}$
}

To cite: Harris ML, Hure AJ, Holliday E, et al. Association between preconception maternal stress and offspring birth weight: findings from an Australian longitudinal data linkage study. BMJ Open 2021;11:e041502. doi:10.1136/ bmjopen-2020-041502

- Prepublication history and additional material for this paper is available online. To view these files, please visit the journal online (http://dx.doi.org/10. 1136/bmjopen-2020-041502).

Received 11 June 2020 Revised 15 February 2021 Accepted 24 February 2021

Check for updates

(c) Author(s) (or their employer(s)) 2021. Re-use permitted under CC BY-NC. No commercial re-use. See rights and permissions. Published by BMJ.

${ }^{1}$ Centre for Women's Health Research, University of Newcastle, Callaghan, New South Wales, Australia

${ }^{2}$ School of Medicine and Public Health, University of Newcastle, Callaghan, New South Wales, Australia

Correspondence to Dr Melissa L Harris; melissa.harris@newcastle. edu.au

\section{ABSTRACT}

Objective Examine the relationship between

preconception stress and offspring birth weight.

Setting Population-based cohort study linked with statebased administrative perinatal data.

Participants 6100 births from 3622 women from the 1973-1978 cohort of the Australian Longitudinal Study of Women's Health who (1) recorded a singleton birth between January 1997 and December 2011; (2) returned at least one follow-up survey within 3 years of conception; and (3) had complete data on perceived stress prior to conception.

Primary outcome measures Linear generalised estimating equations were used to examine the relationship between preconception stress and a continuous measure of birth weight, exploring differences based on birth order and stress chronicity. The minimal sufficient adjustment set of covariates was determined by a directed acyclic graph.

Results For all births, there was no relationship between moderate/high acute or chronic stress and offspring birth weight in grams. Among first births only, there was a trend towards a relationship between moderate/high chronic stress and offspring birth weight. Offspring sex was associated with birth weight in all models, with female babies born lighter than male babies on average, after adjusting for covariates $(p<0.0001)$.

Conclusions Effects of preconception stress on birth weight was largely driven by time to conception. With the timing of stress critical to its impact on obstetrical outcomes, preconception care should involve not only reproductive life planning but the space to provide interventions at critical periods so that optimal outcomes are achieved.

\section{INTRODUCTION}

The intrauterine environment is not only critical for facilitating the growth trajectory of the fetus, but also has long-term health consequences. ${ }^{12}$ Early life programming through an adverse intrauterine environment (via altered structure and function of cells and physiological systems) increases susceptibility to a myriad of diseases. In particular, low birth
Strengths and limitations of this study

- This is the first study to explore the role of preconception perceived stress as a risk factor for birth weight using population level prospective survey data linked with administrative obstetrics data.

- Prospective examination of preconception stress reduced retrospective recall bias.

- The stability of the findings was verified by examining preconception stress and birth weight using multiple definitions as well as accounting for offspring birth order by delineating between first births and all births.

- We were unable to control for pregnancy intentions, which may have confounded the relationship as unintended pregnancies are associated with poorer birth outcomes.

weight (LBW, $<2500 \mathrm{~g}$ ), a crude indicator of suboptimal in utero environment, has been associated with cardiovascular disease, metabolic disorders, psychiatric disease as well as increased risk of neonatal, infant and premature adult mortality. ${ }^{3-5}$ Despite advances in obstetrical care, international rates for LBW have remained relatively stable in developed countries at around $6 \%$ over the past 20 years. ${ }^{6}$ In Australia the proportion of LBW live births has increased from $6.0 \%$ to $6.5 \%$ since $2012 .^{78}$ To achieve optimal birth outcomes, it is important to identify modifiable factors attributable to LBW.

Research has identified a number of modifiable risk factors for LBW including pre-existing and pregnancy-related medical conditions, prenatal care, environmental exposures and adverse health behaviours. ${ }^{9}$ To date, adverse maternal health behaviours such as poor maternal nutrition, tobacco smoking and heavy alcohol use have been the most widely examined. ${ }^{10-12}$ Despite the implementation of antenatal interventions 
based on these risk factors, the incidence of LBW has not reduced. Research in the area requires a shift in focus from individual attribution and responsibility of health behaviours to understanding the inequalities that underpin such behaviours. As such, identifying additional factors that contribute to increased risk of adverse birth outcomes is therefore imperative. Importantly, health behaviour is a multidimensional concept that reflects cumulative life experience and is largely determined by contextual factors and responses to stress (including the development of allostatic load). ${ }^{13}$

The role of stress in poor obstetrical outcomes has received increased attention recently. Much of this research has come from clinic-based studies, ${ }^{14}$ with the findings dependent on how stress is operationalised and the number of additional contributing factors included in the model. A 2014 systematic review of cohort studies found strong evidence for a relationship between stressful life events before or during pregnancy and poor obstetrical outcomes. ${ }^{15}$ The most consistent evidence was for preconception stress. Although few studies have examined preconception stress, Witt and colleagues used national population-level data to find that exposure to at least one stressful life event prior to conception (eg, death of a family member, divorce or fertility problems) increased the odds of having a very LBW baby $(<1500 \mathrm{~g})$ by $38 \% .{ }^{16}$ Similarly, analysis of almost 7000 mother-child dyads, resulted in a small indirect association between women's exposure to stressful preconception life events and offspring poor health at 9 and 24 months, mediated through very LBW. ${ }^{17}$ Another study found that exposure to preconception chronic stressors (those that had enduring impact such as those experienced in childhood), but not acute stressors (events of limited duration), was associated with LBW for first and second births. ${ }^{18}$

Current thinking surrounding the role of stress in health outcomes suggests that stress is complex and involves more than the simple physiological response to a stressor. ${ }^{19}$ High perceived stress in pregnancy was found to be a stronger risk factor for preterm birth than exposure to stressful life events. ${ }^{20}$ Another study found both stressful life events and perceived stress during pregnancy were associated with an increased risk of delivering a very LBW baby. ${ }^{21}$ Less research has examined the role of preconception perceived stress and adverse birth outcomes. However, preconception poor mental health was found to be the most significant risk factor for pregnancy complications, making women $40 \%$ more likely to have a pregnancy complication and nearly twice as likely to give birth to a LBW baby. This suggests that the chronicity of stress (experienced on multiple occasions across time) may be at the core of poor birth outcomes such as LBW. ${ }^{22}$ Further, a relationship between LBW and flattened diurnal cortisol slopes (a proxy for perceived stress) in mothers during the period between one birth to the next has been identified. ${ }^{23}$

In this study, we used longitudinal population-level cohort data linked to administrative birth data to examine the temporal relationship between preconception perceived stress and offspring birth weight. We aimed to explore whether this association differed by stress chronicity (acute vs chronic); and birth order (first birth vs subsequent births).

\section{METHODS}

\section{Overview of study design}

This study involved data from the 1973-1978 cohort of the Australian Longitudinal Study on Women's Health (ALSWH), a national population-based study of health and well-being. Women were randomly sampled through the national health insurer's database (Medicare Australia) with women from rural and remote areas sampled at twice the rate as those from urban areas. ${ }^{24}$ The cohort has been surveyed on roughly a 3-year rolling schedule since 1996. Women who completed follow-up surveys are largely representative of similarly aged women in the population, with a slight over-representation of married, Australian-born and tertiary educated women. ${ }^{25}$ For the current study, ALSWH survey data were linked with state-based administrative perinatal data from New South Wales (NSW), Queensland (QLD) and Western Australia (WA). The perinatal data sets cover all births recorded in state-based public and private hospitals (as well as home births). Data are collected by attending midwives and medical practitioners and provide information on live births and stillbirths of at least 20 weeks' gestation or birth weight of at least $400 \mathrm{~g}$ (except for WA where births are included if gestational age is at least 20 weeks or if gestation is unknown, birth weight is at least $400 \mathrm{~g}$ ). While the specific information provided in these data sets is state dependent, provided information includes maternal demographic characteristics, maternal medical and obstetrical information, labour and delivery information, birth information for the child, as well as maternity and postnatal care (including model of care, place of birth and discharge information). ALSWH data were linked to the NSW, QLD and WA perinatal data sets using probabilistic matching for the period 1997-2011.

\section{Participants}

This study included women and their children from the 1973-1978 cohort (aged 18-23 at baseline). Women from the full cohort $(\mathrm{N}=14247)$ were eligible for inclusion if they (1) resided in one of the eligible states for linkage to the administrative birth records (ie, NSW, QLD or WA) and had a singleton birth recorded in the administrative data sets from January 1997 to December 2011; (2) returned an ALSWH survey in either 1996 (Survey 1), 2000 (Survey 2), 2003 (Survey 3), 2006 (Survey 4) or 2009 (Survey 5) within 3years preceding the estimated conception date (see figure 1); and (3) had complete data on preconception stress in the 3 years preceding the estimated conception date. The estimated conception date was determined using children's date of birth and length of gestation in the administrative data sets. The proportion of women who returned a survey and had a linked singleton birth within 


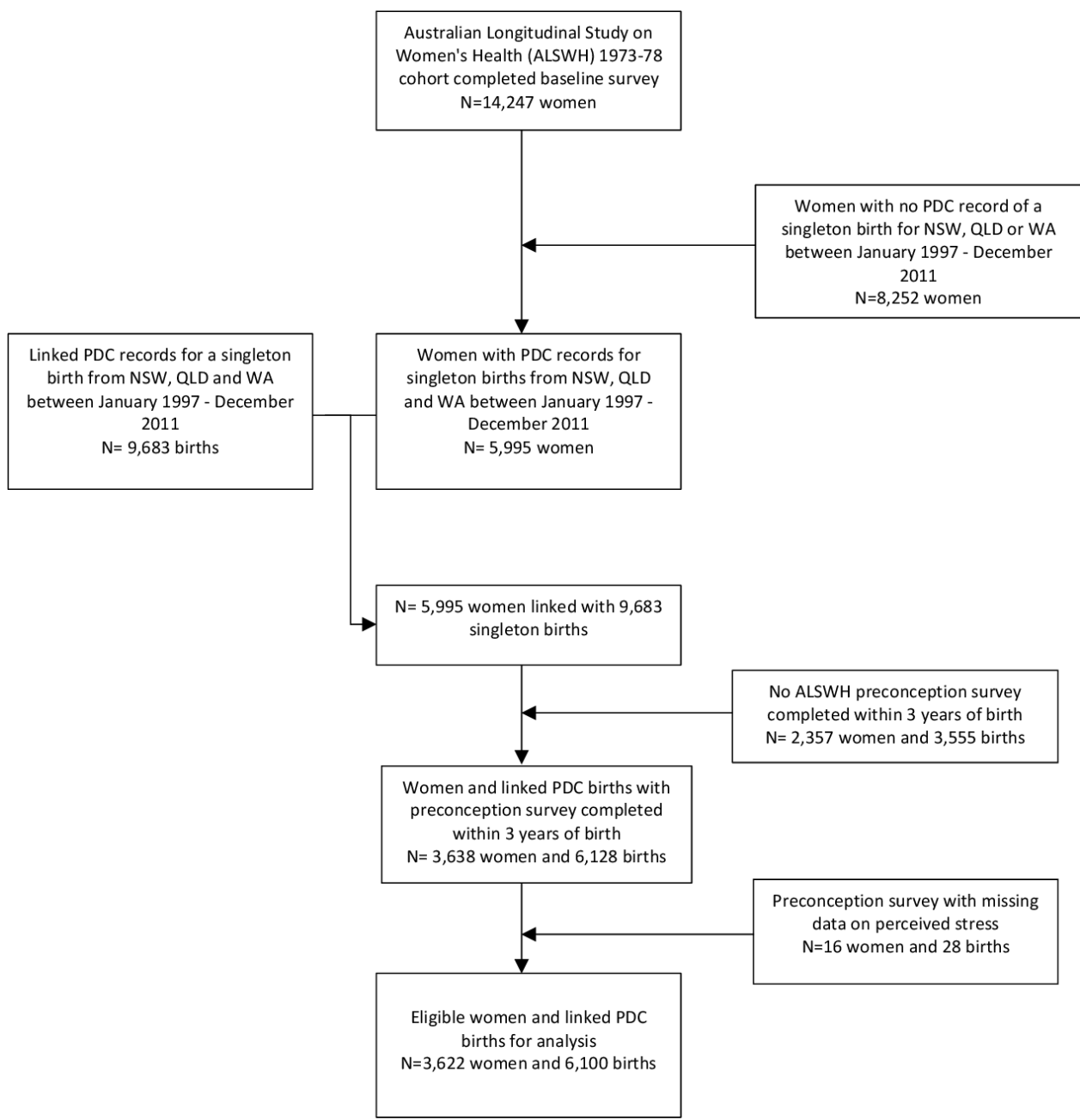

Figure 1 Flow diagram showing the selection of participants, using the 1973-1978 cohort of the ALSWH linked with Perinatal Data Collections (PDC) from New South Wales (NSW), Queensland (QLD) and Western Australia (WA). Women who were not eligible for inclusion ( $\mathrm{N}=8252$ ) resided outside NSW, QLD or WA (eg, Victoria, Tasmania, South Australia, the Australian Capital Territory or the Northern Territory) and could not have their birth records linked; resided within NSW, QLD or WA but did not give birth during the observation period, had a plural birth or had missing data on the exposure. Among eligible women, nearly half of all women (47.6\%) had a single child in the linked data set, 38.7\% had two children and $11.6 \%$ had three children. Only about $2 \%$ of all women had more than three children in the data set (maximum 7). ALSWH data linked to PDC records at each survey included 899 (14.7\% of records) at Survey 1; 1092 (17.9\% of records) at Survey 2, 1630 (26.7\% of records) at Survey 3 , 1827 (30.0\% of records) at Survey 4 and 652 (10.7\% of records) at Survey 5.

3 years following the survey across each of the survey waves is shown in online supplemental table 1. The final sample for analysis included 6100 births from 3622 women.

\section{Measures}

Maternal data were mainly extracted from the ALSWH surveys, whereas offspring data were derived from the linked perinatal data sets.

Outcome: birth weight. Birth weight in grams was treated as a continuous variable (recorded in grams). Analyses were conducted separately for all recorded births and for first births only. A woman's first birth was identified on the basis of: (1) no prior birth recorded in the administrative data and (2) information was provided on the child's date of birth in ALSWH Surveys 3-6 and there was no child date of birth preceding the first observed administrative record. Previous research has demonstrated good agreement between ALSWH recorded births and statebased perinatal data sets. ${ }^{26}$

Main risk factor variable: perceived stress. The Perceived Stress Questionnaire for Young Women (PSQYW) was used to assess preconception levels of perceived stress. Women were asked to rate how stressed they had felt across 10 life domains within a 12-month period. Responses were recorded on a 5-point scale from 'not stressed at all' to 'extremely stressed'. Mean scores over time were computed to reflect the chronicity of preconception stress. Acute stress was determined using the woman's most recent preconception stress score (ie, at the survey prior to conception). Chronic stress was determined for women with two or more stress scores recorded prior to conception (with at least one occurring at the survey prior to conception). Chronic stress scores were 
calculated as the average of all available stress scores up to conception. Given that stress was measured on average every 3 years, chronic stress measures covered a minimum period of 6 years prior to conception and a maximum period of 15 years prior to conception. Similar proportions were noted for women who reported the experience of chronic stress at two, three and four time points $(25 \%-$ $29 \%$ ), with only a small number of women experiencing stress at all five time points. Both chronic and acute stress scores were dichotomised as either none/minimal (score $\leq 1$ ) or moderate/high (score $>1$ and $\leq 4$ ). The PSQYW is an adequate measure of overall perceived stress and is able to capture broad sources of perceived stress for young women. ${ }^{27}$ This scale has demonstrated acceptable internal consistency (Cronbach's alpha $=0.75$ ) for the 1973-1978 cohort, comparable to the commonly used 14-item Perceived Stress Scale, and convergent as well as discriminant validity. ${ }^{28}{ }^{29}$ This measure of perceived stress has been used previously to assess the association between perceived stress and various health outcomes. ${ }^{30-33}$

\section{Covariates}

Maternal and offspring sociodemographics: Marital status (partnered/not partnered), area of residence (major city/inner regional/outer regional/remote) and highest educational qualification (year 12 or less/non-university tertiary education/university or higher) were ascertained from the ALSWH surveys. Maternal age at child's birth, offspring sex (male/female), gestational age (reported in weeks), preterm birth status $(<37$ weeks) and state in which the birth occurred were measured using the administrative data sets.

Health behaviours: Maternal preconception smoking status was categorised as 'non-smoker', 'ex-smoker and 'current smoker'. Alcohol consumption was determined from survey items relating to frequency and quantity, with risk categorised based on Australian National Health and Medical Research Council guidelines into (1) 'nondrinker', (2) 'rarely drinks' (maximum 2 standard drinks per day, $<7$ drinks per week), (3) 'low risk' ( $>7$ and $\leq 14$ drinks per week) and (4) 'high risk' ( $\geq 15$ or more drinks per week). Preconception body mass index (BMI) was calculated based on self-reported height and weight and categorised as underweight $\left(<18.5 \mathrm{~m}^{2}\right)$, healthy weight $\left(18.5-24.99 \mathrm{~m}^{2}\right)$, overweight $\left(25-29.99 \mathrm{~m}^{2}\right)$ and obese $\left(\geq 30 \mathrm{~m}^{2}\right) .34$

Physical and reproductive histories: Diagnosed or treated chronic health conditions experienced in the past 3 years that may impact on birth weight (ie, diabetes, hypertension and asthma), as well as history of miscarriage, were measured using the ALSWH surveys. Given that maternal stress may be causally related to both stillbirth and birth weight, stillbirths were retained in the data set.

All ALSWH covariate measures were obtained from the most recent survey within 3 years prior to conception.

Determining the potential causal pathway in the preconception stress-offspring birth weight

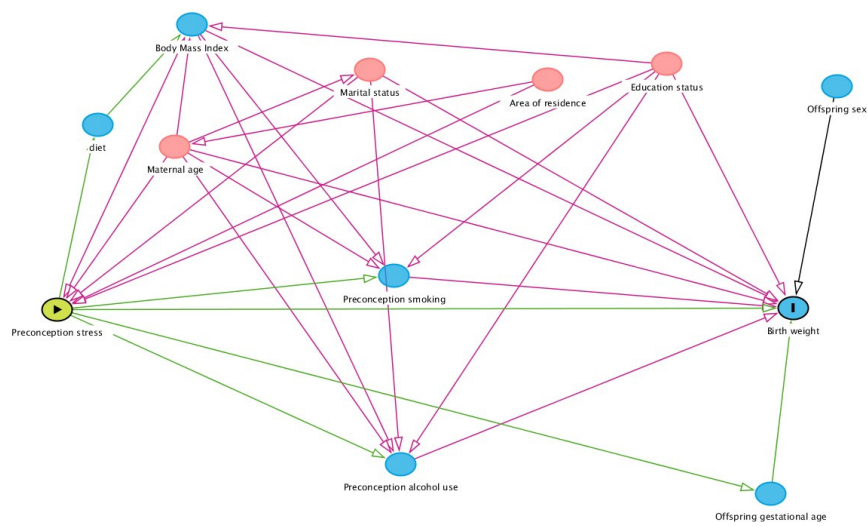

Figure 2 Directed acyclic graph (DAG) showing the hypothesised causal mechanisms between preconception stress (exposure) and birth weight (outcome) taking into account potential measured confounders and mediators. According to the DAG, preconception stress may be mediated through health behaviours such as maternal smoking and alcohol consumption and confounded by factors such as maternal age, marital status, highest educational qualifications and area of residence.

relationship: Measured confounders for which adjustment was required in the multivariate models were identified using a directed acyclic graph (DAG) constructed using DAGitty software (V.2.2) to identify the minimal sufficient adjustment set of covariates (see figure 2). The DAG shows the main exposure (preconception stress) and outcome (offspring birth weight). As perceived stress can influence health behaviours such as maternal smoking and alcohol consumption either directly or indirectly, these were determined to be on the causal pathway between the exposure and outcome (ie, potential mediators). Maternal age, marital status, highest educational qualification and area of residence were identified as potential confounders. Although BMI is included in the causal model, it was determined to be both a mediator and confounder of the preconception stress-birth weight relationship. Given that BMI was assumed to be influenced by both marital status and educational attainment, adjustment for these two variables was determined sufficient to account for confounding by BMI. As such, BMI was excluded from the models. Gestational age was also considered as a mediator of the preconception stressbirth weight relationship and as such was excluded from the model. Offspring sex was presumed to directly influence the outcome only. Although not a confounder, it was included in the model since it may explain variation in the outcome.

\section{Statistical analyses}

Sample characteristics: $X^{2}$ analyses and independent t-tests were used to examine sociodemographic and health-related differences according to LBW status (yes/ no) delineating LBW as $<2500 \mathrm{~g}$.

Estimating the causal effects of preconception stress on birth weight: For analyses including all eligible births for each woman, there was potential non-independence 
(correlation) among the offspring birth weights of the same mother, so linear models in a generalised estimating equation (GEE) framework were used to estimate effects. An exchangeable working correlation matrix was assumed for the GEE. The effect estimate for stress represents the estimated mean change in offspring birth weight (in grams) for women with moderate/high stress compared with none/minimal, adjusted for all covariates.

Linear regressions were performed separately for stress chronicity (acute vs chronic). Subgroup analyses were undertaken by birth order (first birth vs subsequent births). Given the low rate of missing data $(<5 \%)$ in the eligible sample for each analysis, complete case analyses were performed, assuming data were missing completely at random. A sensitivity analysis was also performed with chronic stress measured as a continuous variable (trend in preconception stress over time). Here, using survey return dates, mean stress scores for women with multiple stress scores in the preconception period (with at least one occurring in the 3 years prior to conception) were estimated as a linear change per year between Survey 1 and the most recent preconception survey through linear regression. Stress scores were regressed against the survey return date separately for each woman and the average slope over time was derived. This slope was used as the risk factor variable, adjusting for baseline stress.

Power calculation: Given the fixed sample sizes, detectable differences in mean birth weight between women reporting none/minimal and moderate/high stress were calculated for the subset of first births. A sample size of 2166 with an exposed/unexposed ratio of 0.4 and an SD of $570 \mathrm{~g}$ per exposure group was assumed for the acute stress exposure. At a two-tailed significance level of 0.05 the sample had $80 \%$ power to detect a difference of $76 \mathrm{~g}$ in birth weight between the exposure groups. At significance levels of 0.01 and 0.001 , we had $80 \%$ power to detect differences of $83 \mathrm{~g}$ and $113 \mathrm{~g}$, respectively.

All statistical analyses were programmed using SAS software, V.9.4 of the SAS System for Windows (SAS Institute).

\section{Patient and public involvement}

Patients or the public were not involved in the design, conduct, reporting or dissemination plans of our research. Women provided explicit written consent to participate in the ALSWH as well as for linkage to administrative health records prior to 2005. From 2005, an 'optout' consent process was approved by the data custodians for data linkage, with participants regularly reminded of this process. ALSWH participants who decline health record linkage are excluded from linked data requests.

\section{RESULTS}

\section{Sample characteristics}

There was a total of 6100 linked births for the 3622 women, with 2166 being first births. Among all 3622 women, nearly half $(47.6 \%)$ had a single child, $38.7 \%$ had two children and $11.6 \%$ had three children. Only about $2 \%$ of all women reported more than three children $(\max =7)$. The mean $(\mathrm{SD})$ age of women at birth was 29.8 (3.8) years and time from survey completion to conception was $1.44(0.85)$ years. Cohort characteristics are shown in table 1. Among all 6100 linked births, 217 babies were classified as LBW. Of these women, the majority reported one LBW baby $(\mathrm{n}=184)$, with 15 women reporting two LBW babies $(\mathrm{n}=30)$ and 1 woman reported three LBW babies $(n=3)$. LBW was significantly associated with preterm birth, maternal smoking, alcohol consumption, BMI (particularly for those who were underweight), as well as maternal history of hypertension and asthma. Sample characteristics according to stress chronicity (acute stress and chronic stress) for first births and all births are shown in online supplemental tables 2-5.

\section{Stress chronicity}

High correlation was found between acute and chronic stress measures, both for first births and all births (see online supplemental tables 6 and 7). Among women reporting moderate/high acute stress, approximately $80 \%$ reported moderate/high chronic stress across multiple surveys. Similarly, among women reporting none/minimal acute stress, $83 \%$ reported none/minimal stress across multiple surveys.

\section{The longitudinal relationship between preconception stress and birth weight}

For all births, there was no relationship between moderate/high acute or chronic stress and offspring birth weight in grams (see table 2). In first births only, there was a trend towards a relationship between moderate/ high chronic stress and offspring birth weight. Offspring sex was associated with birth weight in all models, with female babies born lighter than male babies on average, after adjusting for covariates $(\mathrm{p}<0.0001)$. For all births, women who were not partnered also had babies that were on average lighter.

\section{Sensitivity analysis}

Similar findings were reported when stress was considered as a continuous measure (see online online supplemental table 8).

\section{DISCUSSION}

\section{Main finding}

To our knowledge, this is the first study to explore the role of preconception perceived stress as a risk factor for birth weight using population level prospective survey data linked with administrative obstetrical data. We have added to the body of literature surrounding stress and birth outcomes by demonstrating that we were unable to identify a clear association overall between levels of preconception stress and LBW. This contrasts with findings from a recent systematic review that suggested the strongest relationship between stress and poor obstetrical outcomes was associated with the preconception period, 
Table 1 Demographic characteristics of women from the Australian Longitudinal Study of Women's Health 1973-1978 cohort who gave birth during the period 1996-2011, according to low birth weight status

\begin{tabular}{|c|c|c|c|c|c|c|}
\hline Source & Characteristic & Class/statistic & $\begin{array}{l}\text { Birth weight } \\
\geq 2500 \mathrm{~g} \\
\text { (N=5883) \% }\end{array}$ & $\begin{array}{l}\text { Low birth } \\
\text { weight } \\
\text { (N=217) \% }\end{array}$ & $\begin{array}{l}\text { Total } \\
(\mathrm{N}=6100) \%\end{array}$ & $P$ value \\
\hline \multirow[t]{2}{*}{ Admin } & Birth weight (g) & Mean (SD) & $3536(458)$ & $1883(643)$ & $3477(558)$ & \\
\hline & & Missing (n) & & & 0 & \\
\hline \multirow[t]{2}{*}{ Admin } & Gestational age (weeks) & Mean (SD) & $39.3(1.32)$ & $33.6(5.05)$ & $39.1(1.92)$ & $<0.0001$ \\
\hline & & Missing (n) & & & 0 & \\
\hline \multirow[t]{3}{*}{ Admin } & Preterm birth ( $<37$ weeks) & Yes & 3 & 66 & 5 & $<0.0001$ \\
\hline & & No & 97 & 34 & 95 & \\
\hline & & Missing (n) & & & 0 & \\
\hline \multirow[t]{3}{*}{ Admin } & Offspring sex & Male & 51.0 & 53.0 & 51.0 & 0.5806 \\
\hline & & Female & 49.0 & 47.0 & 49.0 & \\
\hline & & Missing (n) & & & 0 & \\
\hline \multirow[t]{4}{*}{ Admin } & PDC state & New South Wales & 55.4 & 53.0 & 55.3 & 0.5950 \\
\hline & & Queensland & 24.7 & 24.4 & 24.7 & \\
\hline & & Western Australia & 19.9 & 22.6 & 20.0 & \\
\hline & & Missing (n) & 0 & 0 & 0 & \\
\hline Admin & Maternal age & Mean (SD) & $29.8(3.81)$ & $29.5(4.23)$ & $29.8(3.83)$ & 0.3735 \\
\hline \multirow[t]{3}{*}{ ALSWH } & Marital status & Partnered & 79 & 77 & 79 & 0.4968 \\
\hline & & Not partnered & 21 & 23 & 21 & \\
\hline & & Missing (n) & & & 26 & \\
\hline \multirow[t]{4}{*}{ ALSWH } & Educational attainment & Year 12 or less & 35 & 35 & 35 & 0.0712 \\
\hline & & Non-university tertiary & 25 & 31 & 25 & \\
\hline & & University or higher degree & 40 & 34 & 40 & \\
\hline & & Missing (n) & & & 121 & \\
\hline \multirow[t]{4}{*}{ ALSWH } & Smoking status & Non-smoker & 57 & 50 & 57 & 0.0015 \\
\hline & & Ex-smoker & 22 & 18 & 22 & \\
\hline & & Current smoker & 21 & 31 & 21 & \\
\hline & & Missing (n) & & & 61 & \\
\hline \multirow[t]{5}{*}{ ALSWH } & Alcohol intake & Non-drinker & 10 & 12 & 10 & 0.0414 \\
\hline & & $\begin{array}{l}\text { Rarely drinks (maximum } 2 \\
\text { standard drinks/day, <7/week) }\end{array}$ & 51 & 42 & 51 & \\
\hline & & Low risk (<=14 drinks/week) & 35 & 44 & 35 & \\
\hline & & High risk ( $\geq 15$ drinks/week) & 3.3 & 2.3 & 3.3 & \\
\hline & & Missing (n) & & & 72 & \\
\hline \multirow[t]{5}{*}{ ALSWH } & Body mass index & Healthy weight & 61 & 49 & 61 & 0.0011 \\
\hline & & Underweight & 4.6 & 9.7 & 4.8 & \\
\hline & & Overweight & 22 & 25 & 22 & \\
\hline & & Obese & 12 & 16 & 12 & \\
\hline & & Missing (n) & & & 695 & \\
\hline \multirow[t]{4}{*}{ ALSWH } & Residential area & Major city & 52 & 55 & 52 & 0.2462 \\
\hline & & Inner regional & 27 & 22 & 27 & \\
\hline & & Outer regional/remote & 21 & 23 & 21 & \\
\hline & & Missing (n) & & & 10 & \\
\hline \multirow[t]{2}{*}{ ALSWH } & History of diabetes & Yes & 0.8 & 0.0 & 0.8 & 0.4169 \\
\hline & & Missing (n) & & & 193 & \\
\hline
\end{tabular}

Continued 


\begin{tabular}{|c|c|c|c|c|c|c|}
\hline Source & Characteristic & Class/statistic & $\begin{array}{l}\text { Birth weight } \\
\geq 2500 \mathrm{~g} \\
(\mathrm{~N}=5883) \%\end{array}$ & $\begin{array}{l}\text { Low birth } \\
\text { weight } \\
(\mathrm{N}=217) \%\end{array}$ & $\begin{array}{l}\text { Total } \\
(\mathrm{N}=6100) \%\end{array}$ & $P$ value \\
\hline ALSWH & & Missing (n) & & & 193 & \\
\hline ALSWH & History of asthma & Yes & 12 & 18 & 12 & 0.0050 \\
\hline ALSWH & & Missing (n) & & & 1186 & \\
\hline
\end{tabular}

Admin, administrative medical record (Perinatal Data Collection (PDC) and Midwives Notification System); ALSWH, Australian Longitudinal Study on Women's Health (self-reported data).

although the evidence was limited..$^{15}$ The findings of the current study have important implications for the delivery of mental health and family planning services prior to conception with the timing of stress exposure critical.

\section{Interpretation}

Our primary finding is supported by research that failed to find an association between preconception stressful life events and small for gestational age.$^{35}$ Only three studies have previously examined preconception stress and birth weight outcomes. ${ }^{161736}$ While these studies found that stress increased the odds of having an LBW baby, they were focused on negative life events, including the loss of a previous child, and not perceived stress. Differences in study findings may also be attributable to highly traumatic life events prior to conception potentially inducing posttraumatic stress disorder (PTSD). PTSD has been linked with reduced offspring birth weight with the effect strongest among those who were still symptomatic. ${ }^{37}$ Preconception perceived stress may play the greatest role in impacting fetal development if still unresolved at the time of conception, thereby contributing to hypothalamicpituitary-adrenal dysregulation and allostatic load. Some evidence suggests that pregnancy-specific stress is associated with a stronger relationship with obstetrical outcomes than general anxiety and perceived stress. ${ }^{38}$

Additionally, women who have experienced prior pregnancy loss are more likely to experience low mood and excess anxiety during a subsequent pregnancy. ${ }^{39}$ Repeated exposure to psychological insult has been found to activate and sensitise the nervous system, where a response to decreasingly intense stimuli such as minor stressors may occur through anticipatory action. ${ }^{40}$ Alternatively, as we found a high correlation between the experience of acute and chronic perceived stress for both first births and all births, with $80 \%$ of women reporting moderate/ high stress across multiple surveys, the impact on fetal outcomes may be influenced by personality. Personality traits have been found to shape not only the perception of an event but also coping with, and physical recovery from stress. ${ }^{41}$ Future research examining preconception stress therefore needs to consider not only the timing of exposure but also type of exposure and coping mechanisms across the life course that may have lasting impacts on birth outcomes, such as unresolved bereavement.

\section{Strengths and limitations}

We were able to examine the impact of preconception perceived stress on offspring birth weight using over 10 years of population-level linked data for women in their prime childbearing years. By prospectively examining preconception stress we were able to reduce retrospective recall bias. We verified the stability of our findings by examining preconception stress and birth weight using multiple definitions as well as accounting for offspring birth order by delineating between first births and all births, with no significant changes in estimates observed. This provides confidence in the study findings. Although we were only able to obtain linked administrative birth data for three of the eight Australian states and territories, our rate of LBW babies was found to be similar to other reports among the Australian population, suggesting that our findings are generalisable. ${ }^{42}$ The linkage of selfreport maternal data to objective administrative birth data added further weight to our findings by reducing participant recall bias. Particularly, we were able to account for length of gestation, an important indicator in LBW.

There were however some limitations. Preconception stress was measured at the survey prior to the estimated date of conception, with the timing of the exposure varying up to a maximum of 3 years preconception. The timing of preconception stress exposure may have been critical to the physiological expression of stress, with preconception stress experienced closer to conception playing a greater role on LBW. Additional research is required to examine perceived stress experienced at regular intervals to establish critical exposure periods as women transition from, and through preconception to the antenatal period. Further, it is possible that the results were underestimated as women who experienced transient but intense levels of stress throughout their lives may not have been classified as having preconception stress. While descriptive data was provided on previous miscarriage, we did not include prospective data on miscarriage as a potential outcome 
Table 2 Linear regression for the relationship between preconception acute and chronic stress ${ }^{*}$ as a predictor of birth weight (grams) for all births and first births among women from the 1973-1978 cohort of the Australian Longitudinal Study on Women's Health during the period 1996-2011

\begin{tabular}{|c|c|c|c|c|}
\hline Variable & Category & Beta coefficient & $95 \%$ lower & 95\% upper \\
\hline \multicolumn{5}{|l|}{ All births $(n=6100)$} \\
\hline \multicolumn{5}{|l|}{ Acute stress } \\
\hline Intercept & & 3548.24 & 3501.99 & 3594.48 \\
\hline Stress category (ref=none/minimal) & Moderate/high stress & -2.57 & -33.95 & 28.82 \\
\hline Offspring sex (ref=male) & Female & -120.22 & -146.15 & -94.29 \\
\hline Maternal age (years) & & 5.59 & 1.09 & 10.09 \\
\hline Marital status (ref=partnered) & Not partnered & -65.93 & -100.05 & -31.80 \\
\hline Education (ref=year 12 or less) & Non-university tertiary & -13.77 & -53.76 & 26.21 \\
\hline Education (ref=year 12 or less) & University or higher degree & 22.77 & -17.18 & 62.72 \\
\hline $\begin{array}{l}\text { Residential area (ref=outer regional/ } \\
\text { remote) }\end{array}$ & Inner regional & 14.31 & -29.78 & 58.40 \\
\hline $\begin{array}{l}\text { Residential area (ref=outer regional/ } \\
\text { remote) }\end{array}$ & Major city & -22.17 & -63.38 & 19.05 \\
\hline \multicolumn{5}{|l|}{ Chronic stress } \\
\hline Intercept & & 3574.21 & 3525.00 & 3623.42 \\
\hline Stress category (ref=none/minimal) & Moderate/high & -19.80 & -55.45 & 15.84 \\
\hline Offspring sex (ref=male) & Female & -135.26 & -162.96 & -107.55 \\
\hline Maternal age (years) & & 4.31 & -1.39 & 10.01 \\
\hline Marital status (ref=partnered) & Not partnered & -46.55 & -83.80 & -9.31 \\
\hline Education (ref=year 12 or less) & Non-university tertiary & -29.70 & -73.27 & 13.86 \\
\hline Education (ref=year 12 or less) & University or higher degree & 13.58 & -28.19 & 55.36 \\
\hline $\begin{array}{l}\text { Residential area (ref=outer regional/ } \\
\text { remote) }\end{array}$ & Inner regional & 10.04 & -36.67 & 56.76 \\
\hline $\begin{array}{l}\text { Residential area (ref=outer regional/ } \\
\text { remote) }\end{array}$ & Major city & -25.88 & -69.50 & 17.73 \\
\hline
\end{tabular}

remote)

First births $(\mathrm{N}=2166)$

\begin{tabular}{|c|c|c|c|c|}
\hline \multicolumn{5}{|l|}{ Acute stress } \\
\hline Intercept & & 3418.22 & 3341.06 & 3495.39 \\
\hline Stress category (ref=none/minimal) & Moderate/high stress & 0.74 & -52.84 & 54.32 \\
\hline Offspring sex (ref=male) & Female & -139.13 & -187.61 & -90.65 \\
\hline Maternal age (years) & & -0.64 & -8.34 & 7.06 \\
\hline Marital status (ref=partnered) & Not partnered & 14.34 & -40.55 & 69.22 \\
\hline Education (ref=year 12 or less) & Non-university tertiary & 8.86 & -59.37 & 77.08 \\
\hline Education (ref=year 12 or less) & University or higher degree & 42.31 & -22.55 & 107.17 \\
\hline $\begin{array}{l}\text { Residential area (ref=outer regional/ } \\
\text { remote) }\end{array}$ & Inner regional & 37.12 & -38.64 & 112.88 \\
\hline $\begin{array}{l}\text { Residential area }(r e f=\text { outer regional/ } \\
\text { remote) }\end{array}$ & Major city & 14.80 & -51.68 & 81.29 \\
\hline \multicolumn{5}{|l|}{ Chronic stress } \\
\hline Intercept & & 3478.34 & 3393.98 & 3562.70 \\
\hline Stress category (ref=none/minimal) & Moderate/high & -52.85 & -106.91 & 1.22 \\
\hline Offspring sex (ref=male) & Female & -165.80 & -217.30 & -114.31 \\
\hline Maternal age (years) & & -5.32 & -14.77 & 4.12 \\
\hline Marital status (ref=partnered) & Not partnered & 48.54 & -11.10 & 108.19 \\
\hline Education (ref=year 12 or less) & Non-university tertiary & -64.50 & -140.49 & 11.49 \\
\hline
\end{tabular}


Table 2 Continued

\begin{tabular}{|c|c|c|c|c|}
\hline Variable & Category & Beta coefficient & $95 \%$ lower & 95\% upper \\
\hline Education (ref=year 12 or less) & University or higher degree & -9.26 & -77.70 & 59.19 \\
\hline $\begin{array}{l}\text { Residential area (ref=outer regional/ } \\
\text { remote) }\end{array}$ & Inner regional & 57.50 & -26.09 & 141.09 \\
\hline $\begin{array}{l}\text { Residential area (ref=outer regional/ } \\
\text { remote) }\end{array}$ & Major city & 36.88 & -34.21 & 107.98 \\
\hline
\end{tabular}

*Binary classification derived from mean stress scores where acute stress (dichotomised as none/minimal and moderate/high) was measured at the most recent survey prior to conception and chronic stress (measured at two or more time points prior to conception including one as the survey prior to conception) was averaged across available data point and dichotomised similarly to acute stress.

related to stress. In addition, as we examined covariates measured in the preconception period, we did not include chronic disease experienced during the gestation period. Gestational hypertension and pre-eclampsia have been found to be key drivers of LBW and small for gestational age. While pre-eclampsia has been associated with preconception blood pressure levels it is likely that the inclusion of these variables would push the result further to the null. ${ }^{43-45}$ We were also unable to adequately capture variables that may have had an influence on the risk factor variable and the outcome like Aboriginal and Torres Strait Islander status and socioeconomic status, although educational attainment is often included in epidemiological research as a proxy for socioeconomic position. ${ }^{46}$ Likewise, we were also unable to control for pregnancy intentions, which may have confounded the relationship as unintended pregnancies are associated with poorer birth outcomes. ${ }^{47}$ Such reproductive health factors and their causal relationship with stress should be explored in future analyses. Similarly, given the crude nature of ILBW as a measure of the in utero environment, the relationship between preconception stress and other fetal outcomes such as gestational age, gestational length and intrauterine growth restriction requires further examination.

\section{Implications and conclusion}

With an increase in research surrounding the effect of stress on health, including long-term and intergenerational transmission, there is the assumption that stress at any point in the lifespan is detrimental to maternal and infant outcomes. However, we need to be cautious about the message that is delivered to young women regarding the role of stress and pregnancy outcomes. The findings from this study suggest that the experience of stress prior to conception does not necessarily impact negatively on birth weight. What we should glean from this is that there are critical periods in which interventions for women who experience stress and mental health concerns may alter vulnerabilities and improve obstetrical outcomes if administered prior to conception.

As part of a life course perspective to women's health, preconception healthcare has received increased attention, although there is still a lack of formalised framework. To date, there has been a strong interest in supporting health behaviour change (eg, smoking, alcohol consumption and obesity) that impact on fertility and obstetrical outcomes with adolescence and young adulthood identified as key intervention points. Preconception health plans that also include stress and mental health interventions will provide early intervention to reduce poor pregnancy outcomes as interventions during pregnancy have been met with limited success. With approximately $40 \%$ of pregnancies among reproductive-aged women unintended, ${ }^{48}$ and these rates markedly higher among women under age 24 years, ${ }^{49}$ waiting to provide mental health interventions in the antenatal period will often be too late to prevent adverse birth outcomes. Preconception care therefore involves not only reproductive life planning but also the space in which to provide interventions so that optimal outcomes are achieved not only for the mother, but also the baby.

Acknowledgements The research on which this paper is based was conducted as part of the Australian Longitudinal Study on Women's Health (ALSWH) by the University of Newcastle and the University of Queensland. This work was supported by the Australian Government Department of Health, which has funded the ALSWH since 1996. We are grateful to the Australian Government Department of Health for funding and to the women who provided the survey data. The authors also acknowledge the NSW Ministry of Health and the staff at the Centre for Health Record Linkage (CHeReL), the Statistical Services Branch at Queensland Health and the Data Linkage Branch at the Department of Health, Western Australia, for undertaking the linkage of the perinatal data. The study team would also like to thank Ms Peta Forder, Senior Statistician, for the ALSWH for child dates of birth data cleaning. Dr Melissa Harris is funded through an Australian Research Council Discovery Early Career Researcher Award (DE190101134).

Contributors MLH, AH, EH, CC, DL and AEA contributed to the study concept. MLH, $\mathrm{AH}$ and $\mathrm{EH}$ contributed to the study design and analysis plan. $\mathrm{EH}$ conducted the analysis. MLH and AH drafted the manuscript. All authors revised the manuscript for intellectual content and approved the final version to be published. All authors are accountable for all aspects of the work in ensuring that questions related to the accuracy or integrity of any part of the work are appropriately investigated and resolved.

Funding This study was supported by the Hunter Children's Research Foundation (G1300904). The funding body played no role in the design, analysis, interpretation of the findings or the decision to submit the manuscript for publication.

Competing interests None declared.

Patient consent for publication Not required.

Ethics approval This project has ongoing ethical clearance from the University of Newcastle and University of Queensland's Human Research Ethics Committees. Ethical approval for linkage of Australian Longitudinal Study on Women's Health survey data to the Perinatal Data Collections (PDC) in New South Wales (NSW) was received from the NSW Population and Health Services Research Ethics Committee (2011/11/357). Approval for use of the Western Australia (WA) Midwives Notification 
System was received from the WA Department of Health Human Research Ethics Committee (2015/47). Approval for linkage of the Queensland (QLD) PDC was covered by the QLD Public Health Act (RD007206).

Provenance and peer review Not commissioned; externally peer reviewed.

Data availability statement Data may be obtained from a third party and are not publicly available. The data used in this analysis belong to the Australian Longitudinal Study on Women's Health. Data will be made available via an Expression of Interest process, described at the study's website (www.alswh.org. au/). This study was conducted under the approved E0I A515.

Supplemental material This content has been supplied by the author(s). It has not been vetted by BMJ Publishing Group Limited (BMJ) and may not have been peer-reviewed. Any opinions or recommendations discussed are solely those of the author(s) and are not endorsed by BMJ. BMJ disclaims all liability and responsibility arising from any reliance placed on the content. Where the content includes any translated material, BMJ does not warrant the accuracy and reliability of the translations (including but not limited to local regulations, clinical guidelines, terminology, drug names and drug dosages), and is not responsible for any error and/or omissions arising from translation and adaptation or otherwise.

Open access This is an open access article distributed in accordance with the Creative Commons Attribution Non Commercial (CC BY-NC 4.0) license, which permits others to distribute, remix, adapt, build upon this work non-commercially, and license their derivative works on different terms, provided the original work is properly cited, appropriate credit is given, any changes made indicated, and the use is non-commercial. See: http://creativecommons.org/licenses/by-nc/4.0/.

\section{ORCID iDs}

Melissa L Harris http://orcid.org/0000-0002-5733-9684

Elizabeth Holliday http://orcid.org/0000-0002-4066-6224

\section{REFERENCES}

1 Barker DJ. The fetal and infant origins of adult disease. BMJ 1990;301:1111.

2 Barker DJ. The fetal and infant origins of disease. Eur J Clin Invest 1995;25:457-63.

3 Gluckman PD, Hanson MA, Cooper C, et al. Effect of in utero and early-life conditions on adult health and disease. N Engl J Med 2008;359:61-73.

4 Malin GL, Morris RK, Riley R, et al. When is birthweight at term abnormally low? A systematic review and meta-analysis of the association and predictive ability of current birthweight standards for neonatal outcomes. BJOG 2014;121:515-26.

5 Risnes KR, Vatten LJ, Baker JL, et al. Birthweight and mortality in adulthood: a systematic review and meta-analysis. Int $\mathrm{J}$ Epidemiol 2011;40:647-61.

6 United Nations Children's Fund (UNICEF) and World Health Organization (WHO). Low birthweight: country, regional and global estimates. New York, NY, USA: UNICEF, 2004.

7 Australian Institute of Health and Welfare. Australia's mothers and babies 2015-in brief. Perinatal statistics series no 33 Cat no PER 91 Canberra: AlHW, 2017.

8 Hilder L, Zhichao Z, Parker M. Australia's mothers and babies 2012. Perinatal statistics series no 30 Cat no PER 69. Canberra: AlHW, 2014.

9 Valero De Bernabé J, Soriano T, Albaladejo R, et al. Risk factors for low birth weight: a review. Eur J Obstet Gynecol Reprod Biol 2004;116:3-15.

10 Gresham E, Byles JE, Bisquera A, et al. Effects of dietary interventions on neonatal and infant outcomes: a systematic review and meta-analysis. Am J Clin Nutr 2014;100:1298-321.

11 Juárez SP, Merlo J. Revisiting the effect of maternal smoking during pregnancy on offspring birthweight: a quasi-experimental sibling analysis in Sweden. PLoS One 2013;8:e61734.

12 Patra J, Bakker R, Irving H, et al. Dose-response relationship between alcohol consumption before and during pregnancy and the risks of low birthweight, preterm birth and small for gestational age (SGA)-a systematic review and meta-analyses. BJOG 2011;118:1411-21.

13 Barrett ES, Vitek W, Mbowe O, et al. Allostatic load, a measure of chronic physiological stress, is associated with pregnancy outcomes, but not fertility, among women with unexplained infertility. Hum Reprod 2018;33:1757-66.

14 Rondó PHC, Ferreira RF, Nogueira F, et al. Maternal psychological stress and distress as predictors of low birth weight, prematurity and intrauterine growth retardation. Eur J Clin Nutr 2003;57:266-72.
15 Witt WP, Litzelman K, Cheng ER, et al. Measuring stress before and during pregnancy: a review of population-based studies of obstetric outcomes. Matern Child Health J 2014;18:52-63.

16 Witt WP, Cheng ER, Wisk LE, et al. Maternal stressful life events prior to conception and the impact on infant birth weight in the United States. Am J Public Health 2014;104 Suppl 1:S81-9.

17 Cheng ER, Park H, Wisk LE, et al. Examining the link between women's exposure to stressful life events prior to conception and infant and toddler health: the role of birth weight. J Epidemiol Community Health 2016;70:245-52.

18 Strutz KL, Hogan VK, Siega-Riz AM, et al. Preconception stress, birth weight, and birth weight disparities among US women. Am J Public Health 2014;104:e125-32.

19 Lazarus RS, Folkman S. Transactional theory and research on emotions and coping. Eur J Pers 1987;1:141-69.

20 Ghosh JKC, Wilhelm MH, Dunkel-Schetter C, et al. Paternal support and preterm birth, and the moderation of effects of chronic stress: a study in Los Angeles County mothers. Arch Womens Ment Health 2010;13:327-38.

21 Sable MR, Wilkinson DS. Impact of perceived stress, major life events and pregnancy attitudes on low birth weight. Fam Plann Perspect 2000;32:288-94.

22 Witt WP, Wisk LE, Cheng ER, et al. Preconception mental health predicts pregnancy complications and adverse birth outcomes: a national population-based study. Matern Child Health $J$ 2012;16:1525-41.

23 Guardino CM, Schetter CD, Saxbe DE, et al. Diurnal salivary cortisol patterns prior to pregnancy predict infant birth weight. Health Psychol 2016;35:625-33.

24 Brown WJ, Bryson L, Byles JE, et al. Women's health Australia: recruitment for a national longitudinal cohort study. Women Health 1998;28:23-40.

25 Lee C, Dobson AJ, Brown WJ, et al. Cohort profile: the Australian longitudinal study on women's health. Int J Epidemiol 2005;34:987-91.

26 Gresham E, Forder P, Chojenta CL, et al. Agreement between selfreported perinatal outcomes and administrative data in New South Wales, Australia. BMC Pregnancy Childbirth 2015;15:161.

27 Bell S, Lee C. Development of the perceived stress questionnaire for young women. Psychol Health Med 2002;7:189-201.

28 Bell S, Lee C. Perceived stress revisited: The Women's Health Australia project Young cohort. Psychol Health Med 2003;8:343-53.

29 Cohen S, Williamson G. Perceived stress in a probability sample of the United States. In: Spacapan S, Oskamp S, eds. The social psychology of health. Newbury Park, CA: Sage Publications Inc, 1988: 31-67.

30 Harris ML, Loxton D, Sibbritt DW, et al. The influence of perceived stress on the onset of arthritis in women: findings from the Australian longitudinal study on women's health. Ann Behav Med 2013;46:9-18.

31 Harris ML, Oldmeadow C, Hure A, et al. Stress increases the risk of type 2 diabetes onset in women: a 12-year longitudinal study using causal modelling. PLoS One 2017;12:e0172126.

32 Damone $\mathrm{AL}$, Joham $\mathrm{AE}$, Loxton $\mathrm{D}$, et al. Depression, anxiety and perceived stress in women with and without PCOS: a communitybased study. Psychol Med 2019;49:1510-20.

33 Ball K, Schoenaker DAJM, Mishra GD. Does psychosocial stress explain socioeconomic inequities in 9-year weight gain among young women? Obesity 2017;25:1109-14.

34 WHO Consultation on Obesity. Obesity: report to who consultation Geneva: World Health Organization, 1999.

35 Precht DH, Andersen PK, Olsen J. Severe life events and impaired fetal growth: a nation-wide study with complete follow-up. Acta Obstet Gynecol Scand 2007;86:266-75.

36 Khashan AS, McNamee R, Abel KM, et al. Reduced infant birthweight consequent upon maternal exposure to severe life events. Psychosom Med 2008;70:688-94.

37 Yonkers KA, Smith MV, Forray A, et al. Pregnant women with posttraumatic stress disorder and risk of preterm birth. JAMA Psychiatry 2014;71:897-904.

38 Kramer MS, Lydon J, Séguin L, et al. Stress pathways to spontaneous preterm birth: the role of stressors, psychological distress, and stress hormones. Am J Epidemiol 2009;169:1319-26.

39 Chojenta C, Harris S, Reilly N, et al. History of pregnancy loss increases the risk of mental health problems in subsequent pregnancies but not in the postpartum. PLoS One 2014;9:e95038.

40 Perry BD, Pollard RH, Blakley TL. Childhood trauma, the neurobiology of adaptation, and "use-dependent" development of the brain: How "states" become "traits". Infant Ment Health 1995;16:271-91. 
41 Childs E, White TL, de Wit H. Personality traits modulate emotional and physiological responses to stress. Behav Pharmacol 2014;25:493-502.

42 Hilder L, Zhichao Z, Parker M. Australia's mothers and babies 2012 Perinatal statistics series no.30. Cat. no.PER69. Canberra: AlHW, 2014.

43 Magnussen EB, Vatten LJ, Myklestad K, et al. Cardiovascular risk factors prior to conception and the length of pregnancy: populationbased cohort study. Am J Obstet Gynecol 2011;204:526.e1-526.e8.

44 Bakker R, Steegers EAP, Hofman A, et al. Blood pressure in different gestational trimesters, fetal growth, and the risk of adverse birth outcomes: the generation $\mathrm{R}$ study. Am J Epidemiol 2011;174:797-806

45 Harville EW, Viikari JSA, Raitakari OT. Preconception cardiovascular risk factors and pregnancy outcome. Epidemiology 2011;22:724-30.
46 Galobardes B, Shaw M, Lawlor DA, et al. Indicators of socioeconomic position (Part 1). J Epidemiol Community Health 2006;60:7-12.

47 Hall JA, Benton L, Copas A, et al. Pregnancy intention and pregnancy outcome: systematic review and meta-analysis. Matern Child Health J 2017;21:670-704.

48 Sedgh G, Singh S, Hussain R. Intended and unintended pregnancies worldwide in 2012 and recent trends. Stud Fam Plann 2014;45:301-14.

49 Coombe J, Harris ML, Wigginton B, et al. Contraceptive use at the time of unintended pregnancy: findings from the contraceptive use, pregnancy intention and decisions study. Aust Fam Physician 2016;45:842-8. 